\title{
Heterozygosity for an Exon 12 Splicing Mutation and a W234G Missense Mutation in an American Child With Chronic Tyrosinemia Type 1
}

\author{
Si Houn Hahn, Donna Krasnewich, Mark Brantly, Eli Anne Kvittingen, and William A. Gahl* \\ Section on Human Biochemical Genetics, Human Genetics Branch, NICHD, NIH, Bethesda, Maryland 20892; Institute of \\ Clinical Biochemistry, University of Oslo, Oslo, Norway; Fax: 301-402-0234
}

Communicated by David Valle

\begin{abstract}
Hereditary tyrosinemia type 1 , an autosomal recessive disorder caused by deficiency of fumarylacetoacetate hydrolase (FAH), manifests in either an acute or a chronic form. We used reverse transcription and the polymerase chain reaction to amplify the FAH cDNA of a 12-year-old American boy with chronic tyrosinemia type 1 . The patient is a compound heterozygote for mutations in the FAH gene. One allele contains a missense mutation in codon 234 changing a tryptophan to a glycine; this allele was of maternal origin. Mutagenesis and transfection into COS cells demonstrated that the W234G mutation abolishes FAH activity. The patient's paternally derived allele is a splicing mutation in the +5 position of intron 12 , causing either insertion of a $105 \mathrm{bp}$ fragment due to a cryptic splice site, or skipping of exon 12, or skipping of both exons 12 and 13 . The chronic phenotype of tyrosinemia type 1 in this patient may be due to some residual, correct splicing by the allele with the splicing mutation. (c) 1995 Wiley-Liss, Inc.
\end{abstract}

KEY WORDs: Tyrosinemia, Fumarylacetoacetate hydrolase, Splicing, Missense, Transfection

\section{INTRODUCTION}

Tyrosinemia type 1, an autosomal recessive inborn error of metabolism, occurs in both an acute and a chronic form (Goldsmith and Laberge, 1989). Clinical characteristics of the acute form include hepatic failure and death in infancy, whereas children with the chronic form have renal tubular dysfunction and hypophosphatemic rickets, progressive liver disease with development of hepatocellular carcinoma (Weinberg et al., 1976), and occasionally porphyria-like neurological crises (Mitchell et al., 1990). The basic defect in tyrosinemia type 1 is deficiency of the enzyme fumarylacetoacetate hydrolase (FAH), and the severity of the disease probably depends upon the amount of residual hepatic FAH activity in an affected individual (Tanguay et al., 1993). FAH catalyzes the cleavage of fumarylacetoacetate to fumarate and acetoacetate; its absence results in the accumulation of fumarylacetoacetate and maleylacetoacetate, which are alkylating agents presumed responsible for the liver damage.

The diagnosis of tyrosinemia type 1 is suggested by elevated plasma tyrosine, supported by in-

1995 WILEY.LISS, INC. *This article is a US Government work and, as such, is in the public domain in the United States of America. creased urinary succinylacetone, and confirmed by reduced FAH activity in cultured fibroblasts. Prenatal and heterozygote diagnoses are based upon biochemical analysis (Laberge et al., 1990) and evaluation of restriction fragment length polymorphisms, which have been determined for the FAH locus (Rootwelt et al., 1992). Therapy of tyrosinemia type 1 includes replacement of renal losses and symptomatic treatment of liver impairment. Restriction of dietary tyrosine and phenylalanine can improve or attenuate symptoms, but the only definitive therapy for the liver disease is transplantation (Paradis et al., 1990). Recently, antimetabolite therapy with 2-(2-nitro-4-trifluoromethylbenzoyl) -1,3-cyclohexanedione, a specific inhibitor of 4-hydroxyphenylpyruvate deoxygenase, has shown great promise (Lindstedt et al., 1992; Scott et al., 1994).

The FAH cDNA has been cloned and localized to region q23-25 of chromosome 15 in humans

\footnotetext{
Received July 8, 1994; accepted January 24, 1995.

*To whom reprint requests/correspondence should be addressed.
} 
(Agsteribbe et al., 1990; Phaneuf et al., 1991). The genomic structure of the FAH gene features 14 exons spanning $\sim 35 \mathrm{~kb}$ of DNA (Labelle et al., 1993). The mouse homologue of the FAH locus is the hsdr-1 locus (Grompe and Al-Dhalimy, 1994), and an animal model is provided by albino mice homozygous for deletions encompassing the alf/hsdr-1 locus on chromosome 7 (Klebig et al., 1992; Ruppert et al., 1992).

Since it is estimated that $\sim 7 \%$ of the population of the Lac St. Jean area of Quebec, Canada, is heterozygous for FAH deficiency (De Braekeleer and Larochelle, 1990), it is not surprising that the first human mutation reported in hereditary tyrosinemia type 1 was in a French-Canadian patient. That mutation, a change in codon 16 of the FAH cDNA (Phaneuf et al., 1992), proved to be an uncommon alteration, but a splicing mutation in intron 12 has been found with a frequency of 77.6\% among Quebec patients with tyrosinemia type 1 (Grompe and Al-Dhalimy, 1993; Tanguay et al., 1993). Two nonsense mutations also have been discovered in patients from mixed ethnic backgrounds, including French-Canadian ancestry (Grompe and Al-Dhalimy, 1993), and an Ala134Asp and a Pro342Leu mutation have been reported in Norwegian patients with chronic tyrosinemia (Rootwelt et al., 1994).

We now report an American patient with chronic tyrosinemia who demonstrated heterozygosity for a Trp234Gly missense mutation as well as a splicing mutation in intron 12 .

\section{Cells}

\section{MATERIALS AND METHODS}

Normal cell strains 5757 and 5659 were obtained from the Human Genetics Mutant Cell Repository (Camden, NJ). COS cells were purchased from ATCC (Rockville, MD). Cultured fibroblasts from the tyrosinemia type 1 patient were grown from a $4 \mathrm{~mm}$ punch biopsy obtained after informed consent. The cells were grown at $37^{\circ} \mathrm{C}$ in Dulbecco's Modified Eagle's Medium containing 10\% fetal calf serum (GIBCO BRL, Gaithersburg, MD), glutamine $(2 \mathrm{mM})$, penicillin $(100 \mathrm{IU} / \mathrm{ml})$ and streptomycin $(100 \mu \mathrm{g} / \mathrm{ml})$, and were maintained under an ambient $\mathrm{CO}_{2}$ content of $5 \%$.

\section{FAH Enzyme Assay}

Fibroblasts or COS cells were washed twice with PBS, scraped into $1 \mathrm{ml}$ of PBS, resuspended in 400 $\mu l$ of $0.25 \mathrm{M}$ sucrose, and sonicated for $15 \mathrm{sec}$. After centrifugation at $48,000 \mathrm{~g}$ for $2 \mathrm{hr}$, the supernatant was applied to a Sephadex G-50 column and eluted with an equal volume of $0.25 \mathrm{M}$ sucrose. Hydrolytic activity of FAH was measured as a decrease in optical density at $330 \mathrm{~nm}$ using fumarylacetoacetate as substrate (Kvittingen et al., 1983). One unit of FAH activity hydrolyzed 1 $\mu$ mole of fumarylacetoacetate/min under the conditions described. Protein concentration was measured using the bicinchoninic acid method (Smith et al., 1985).

\section{cDNA Synthesis Using RT PCR}

Poly A mRNA was extracted from fibroblasts using the microFastTrack system (InVitrogen, San Diego, CA). First strand cDNA from $1 \mu g$ of mRNA was prepared with oligo dT primer in a volume of $20 \mu \mathrm{l}$ as described by the manufacturer (GIBCO BRL, Gaithersburg, MD). The reverse transcriptase reaction product was subjected to PCR amplification to make double-stranded FAH cDNA as two overlapping fragments. The first fragment, for nucleotide positions -50 to 720 , used as primers 5'GCTCTCCGCACGCCACCT. TAGGCC-3' and 5'-CTGAATGTCTCGTGCACTCCAGTC-3'. The second fragment used 5'-AGATTGGGAGAGCGATCCCCATT - ${ }^{\prime}$ ' as the $5^{\prime}$ primer beginning at nucleotide 631 , and either 5'-CCAGAAGAGCAGAGAAAATCT. CATG-3' (for the $3^{\prime}$ primer ending in position 1280 ) or 5'-GCAGGCCTCAGAGCACAATGGC-3' (for the 3' primer ending in nucleotide position 1391). All base positions are given according to the cDNA nomenclature of Phaneuf et al. (1991). PCR amplification was performed under the following conditions: one cycle of $3 \mathrm{~min}$ denaturation at $95^{\circ} \mathrm{C}$ followed by 30 cycles of $95^{\circ} \mathrm{C}$ for $1 \mathrm{~min}, 60^{\circ} \mathrm{C}$ for $1 \mathrm{~min}$, and $72^{\circ} \mathrm{C}$ for $2 \mathrm{~min}$, and a final extension at $72^{\circ} \mathrm{C}$ for $7 \mathrm{~min}$.

The PCR product was cloned into a TA Cloning vector (InVitrogen) and was sequenced using the Sequenase kit (United States Biochemicals, Cleveland, $\mathrm{OH}$ ).

\section{Genomic DNA Sequencing}

Genomic DNA was isolated from fibroblasts as described (Sambrook et al., 1989) and $1 \mu \mathrm{g}$ was submitted for PCR amplification. For the missense mutation, the primers used were 5'-AAGGCCCATGAGCACATTTT $-3^{\prime}$ and 5' $^{\prime}$-ACTCTTCCCAAGGAATGGCC-3', resulting in a PCR product $905 \mathrm{bp}$ long. The exon-intron boundary containing the patient's splice mutation was amplified with the primers 5'-GCAGCAGCTCACTCACCACT $-3^{\prime}$ and 5'-CCGTCCAGCAGAAACTTCCT $-3^{\prime}$. The resulting PCR product was 
880 bp long. Exon 13 and its intron boundary were amplified using the primers $5^{\prime}$-CTTTCTTCCCTTTCCTGTGAGT-3' and 5'-GCAGCTAGAACAGTGCATGGC- ${ }^{\prime}$, resulting in a 206 bp product. The PCR program for each of the above reactions was the same as for $\mathrm{CDNA}$ synthesis. The $\mathrm{PCR}$ reaction contained $10 \mathrm{mM}$ Tris- $\mathrm{HCl}, \mathrm{pH} 9.0$, $50 \mathrm{mM} \mathrm{KCl}, 2.0 \mathrm{mM} \mathrm{MgCl} 2,0.001 \%$ (wt/vol) gelatin, $200 \mu \mathrm{M}$ of each dNTP, 20 pmol of sense and antisense primers, and 2.5 units of Taq DNA polymerase (Perkin Elmer Cetus, Norwalk, CT). Each fragment was cloned into vectors and several clones were sequenced.

\section{Northern Blot Analysis}

Poly A mRNA from fibroblasts was isolated as described above, electrophoresed on a $1.2 \%$ formaldehyde agarose gel, and transferred to nitrocellulose paper (Sambrook et al., 1989). The filter was prehybridized for $6 \mathrm{hr}$ followed by hybridization for $24 \mathrm{hr}$ with random-primer labeled ${ }^{32} \mathrm{P}$ FAH cDNA. The filter was washed and exposed to $\mathrm{X}$-ray film at $-70^{\circ} \mathrm{C}$. After stripping, the filter was reprobed with $\beta$-actin cDNA probe as an internal standard.

\section{Mutagenesis and Expression}

FAH cDNA inserted into a pSVL plasmid vector (Pharmacia, Piscataway, NJ) was kindly provided by Dr. Janice Chou of the NICHD. To construct an FAH clone containing the single base substitution, PCR mutagenesis was employed based upon the method of Mullis et al. (1986). Mutagenesis PCR primers were designed to be complementary to the FAH sequence except for a single base change introduced into the center of the primer. Hence, the primers were 5', CTTATGAACGACG ${ }^{*}$ GGAGTGCACGAG-3' and $5^{\prime}$-CTCGTGCACTCCC ${ }^{*}$ GTCGTTCAT. AAG-3'. A second set of distal primers was designed to be complementary to the adjacent area of the pSVL plasmid. The second PCR product was blunt-ended, cloned into the Sma 1 site of pSVL, and sequenced to ensure that no other mutations had been introduced.

COS cells were harvested by trypsinization $24 \mathrm{hr}$ before transfection and replated in $100 \mathrm{~mm}$ tissue culture dishes at $\sim 20 \%$ confluency. The cells were incubated for $20-24 \mathrm{hr}$ at $37^{\circ} \mathrm{C}$ in a humidified incubator in an atmosphere of $5 \% \mathrm{CO}_{2}$. Equal amounts of each pSVL plasmid, containing either FAH cDNA, mutant cDNA, or no DNA were transfected into COS cells by calcium phosphate coprecipitation, as described by Ausubel et al.
(1987). Three days after transfection, the COS cells were harvested for measurement of FAH enzymatic activity (see above) and total RNA. For this, total RNA from each plate was isolated by RNAzol (Cinna/Biotecx, Friendswood, TX), and equal amounts were blotted onto nitrocellulose paper using the Minifold II slot-blot system from Schleicher and Schuell Co (Keene, NH). Hybridization and washing steps were the same as described for the Northern blots.

\section{RESULTS}

\section{Case Summary}

This 12 -year-old white male was the 9-pound, 4-oz product of a 41-week gestation delivered by caesarean section for failure to progress. The parents were unrelated; the father was of Scottish and German extraction, the mother of French-Canadian extraction. Early growth and general health were unremarkable except for bowing of the lower extremities noted upon ambulation at 1 year of age. At 23 months of age, rickets was diagnosed and treated with vitamin $D$ and phosphate supplementation. A generalized aminoaciduria was also present, with tyrosinuria. Plasma tyrosine was 460 $\mu \mathrm{M}$ (normal, 31-71 $\mu \mathrm{M}$ ); phenylalanine was 71 $\mu \mathrm{M}$ (normal, 26-61 $\mu \mathrm{M}$ ). Urine succinylacetone level was grossly elevated at $1,442 \mathrm{nmol} / \mathrm{mg}$ creatinine.

A restricted tyrosine and phenylalanine diet was initiated at $31 / 2$ years of age. The plasma $\alpha$-fetoprotein level, $1,500 \mathrm{ng} / \mathrm{ml}$ on diagnosis, gradually decreased to $\sim 20 \mathrm{ng} / \mathrm{ml}$, where it has remained. The patient experienced a growth spurt and remains at the 10th percentile for height and the 50th percentile for weight. Liver ultrasounds, performed every 3 months, consistently show a coarse echotexture without masses. On two occasions in the past 2 years, liver ultrasound has suggested possible masses, unconfirmed by follow-up MRI studies. General health and development have been normal.

\section{Fibroblast FAH Activity}

Fumarylacetoacetate hydrolase activity in the patient's fibroblasts was 0.15 units/g protein (normal, 2.3-3.9 units/g protein). The mother's fibroblasts displayed an activity of 1.5 units/g protein (Table 1).

\section{Mutational Analysis}

RT PCR showed no difference in size between normal and patient FAH cDNA in the nucleotides between -50 and 720 . However, RT PCR of the 
TABLE 1. FAH Enzymatic Activity in Fibroblasts and Transfected COS Cells

\begin{tabular}{lc}
\hline Cell type & $\begin{array}{c}\text { FAH activity } \\
\text { (units/g protein) }\end{array}$ \\
\hline Fibroblasts & 0.15 \\
Patient & 1.5 \\
Mother & $2.3-3.9$ \\
Normal control & 0 \\
COS cells transfected with & 0 \\
No DNA ( $=2)$ & $7.6 \pm 2.2$ \\
pSLV (n=2) & 0 \\
pSVLFAH $(n=5)$ & pSVLFAH(W234G) $(n=2)$
\end{tabular}

aProtein from a 48,000 g supernatant (30-300 $\mu \mathrm{g})$ was assayed as described in Materials and Methods.

patient's FAH CDNA in the region between nucleotides 631 and 1391 revealed the normal $760 \mathrm{bp}$ product as well as a fragment $\sim 100 \mathrm{bp}$ larger (Fig. $1 A$ ). When RT PCR was performed using primers between nucleotides 631 and 1,280 , a single 649 bp band was apparent in the normal control, but the patient exhibited three different bands of 649 , 547, and 429 bp (Fig. 1B). Several clones representing each band were sequenced; the $649 \mathrm{bp}$ fragment exhibited a $T$ to $G$ transversion resulting in a glycine for tryptophan substitution in codon 234 (Fig. 2A). Some normal sequences were also identified. This missense mutation was confirmed by genomic DNA sequencing, and the patient's mother was found to have the same W234G mutation in one allele by sequencing her genomic DNA.

Sequencing of several clones of the $547 \mathrm{bp}$ piece revealed that it lacked a $102 \mathrm{bp}$ fragment that coincided exactly with exon 12 . The 429 bp product was missing both exon 12 and the 118 bp exon 13 . Sequencing of genomic DNA showed no deletion, but a $G$ to $A$ transition in the fifth base of intron 12, within the splice donor consensus region (Fig. 2B). The same mutation was demonstrated in the father's DNA by sequencing of the genomic DNA (data not shown). The mother lacked this mutation. No other mutations were found in the patient's genomic DNA; specifically, intron 13 had a normal sequence.

\section{Fibroblast FAH mRNA}

Northern blot analysis of the patient's fibroblasts showed abundant expressed FAH message (Fig. 3). Densitometric quantification indicated that the patient's FAH mRNA was approximately half the amount of that in a normal control. The patient's mother had an mRNA content indistinguishable from normal.
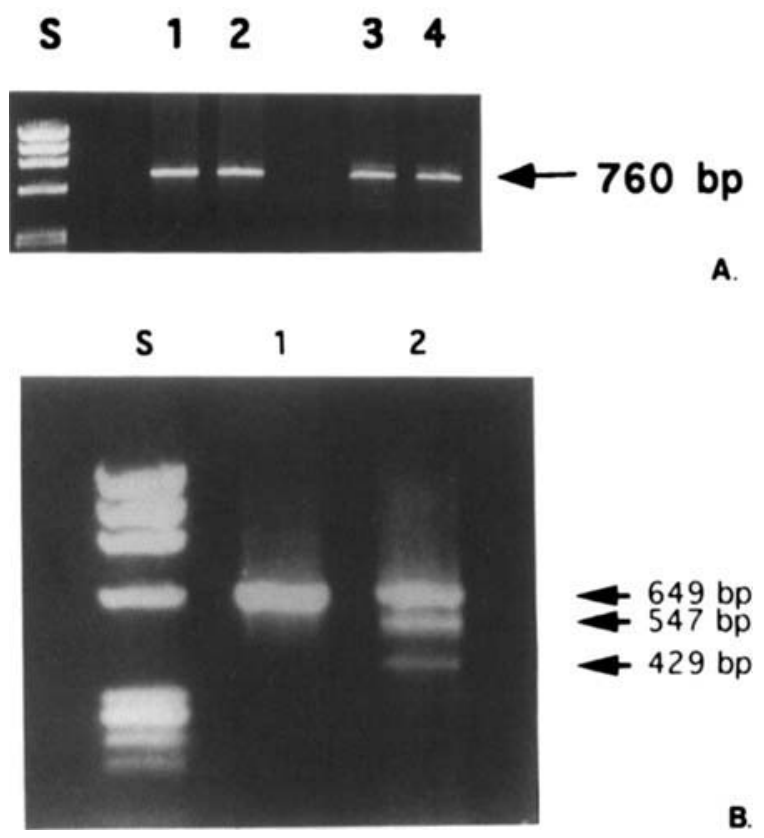

FIGURE 1. Amplification of FAH cDNA. A. PCR of nucleotides 631-1391. Lane $S$ shows the standard OX174/Hae III markers; lanes 1 \& 2, normal FAH cDNA ( 760 bp); lanes $3 \&$ \&, patient CDNA (760 bp plus a large fragment.) B. PCR of nucleotides 631-1280. Lane $S$, size markers; lane 1, normal control (649 bp); lane 2, patient $(649,547, \& 429$ bp fragments). Electrophoresis of the RT PCR product was performed in an ethidium bromide-stained, $1.2 \%$ agarose gel.

\section{Expression of the W234G Allele in COS Cells}

To determine whether the W234G allele functions in expressing FAH activity, a pSVL vector containing the FAH (W234G) cDNA was transfected into COS cells. Both FAH enzymatic activity and FAH RNA were determined. Neither COS cells themselves nor COS cells transfected with pSVL vector alone had measurable FAH activity (Table 1). COS cells transfected with pSVL FAH served as a positive control and exhibited substantial FAH activity. However, COS cells transfected with pSVL FAH(W234G) contained virtually no FAH activity. In contrast, the pSVLFAH(W234G)-transfected COS cells contained abundant FAH RNA by slot blot analysis (Fig. 4), equivalent in amount to that within pSVLFAHtransfected COS cells. No significant FAH RNA was detected in untransfected or pSVL-transfected COS cells.

\section{DISCUSSION}

Mutational analysis in a metabolic disorder can help elucidate genotype/phenotype correlations and can provide valuable information about the mutant protein's structure/function relationships. 

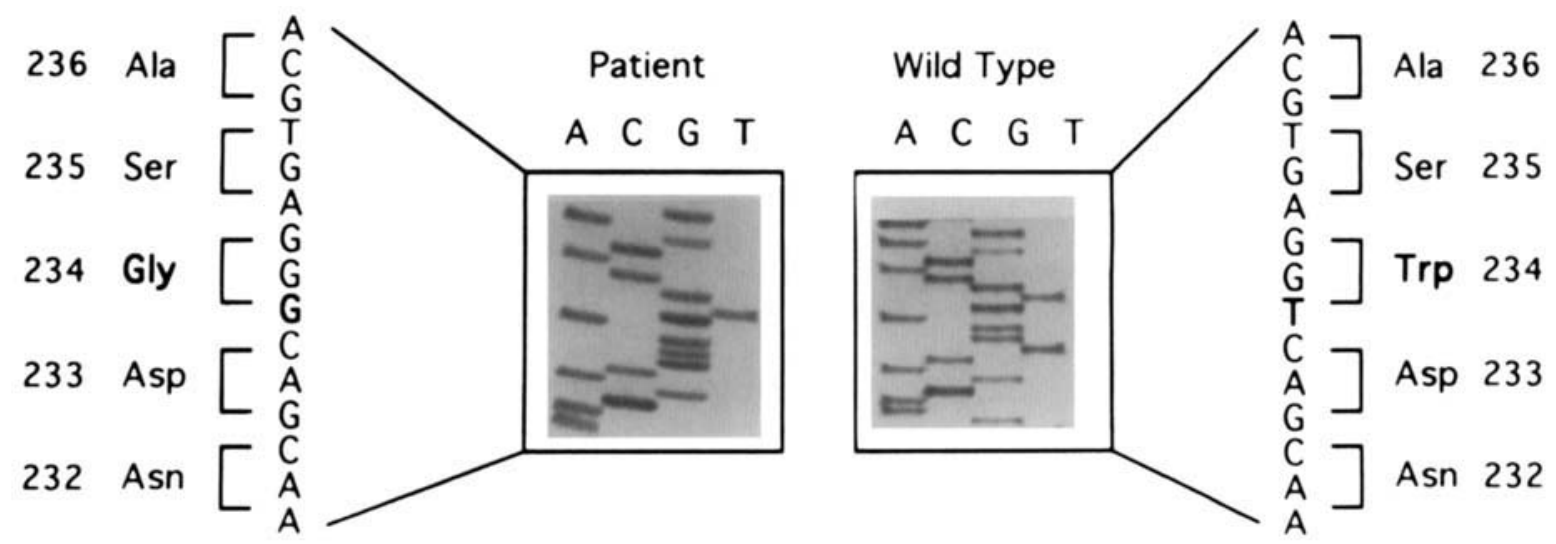

A.

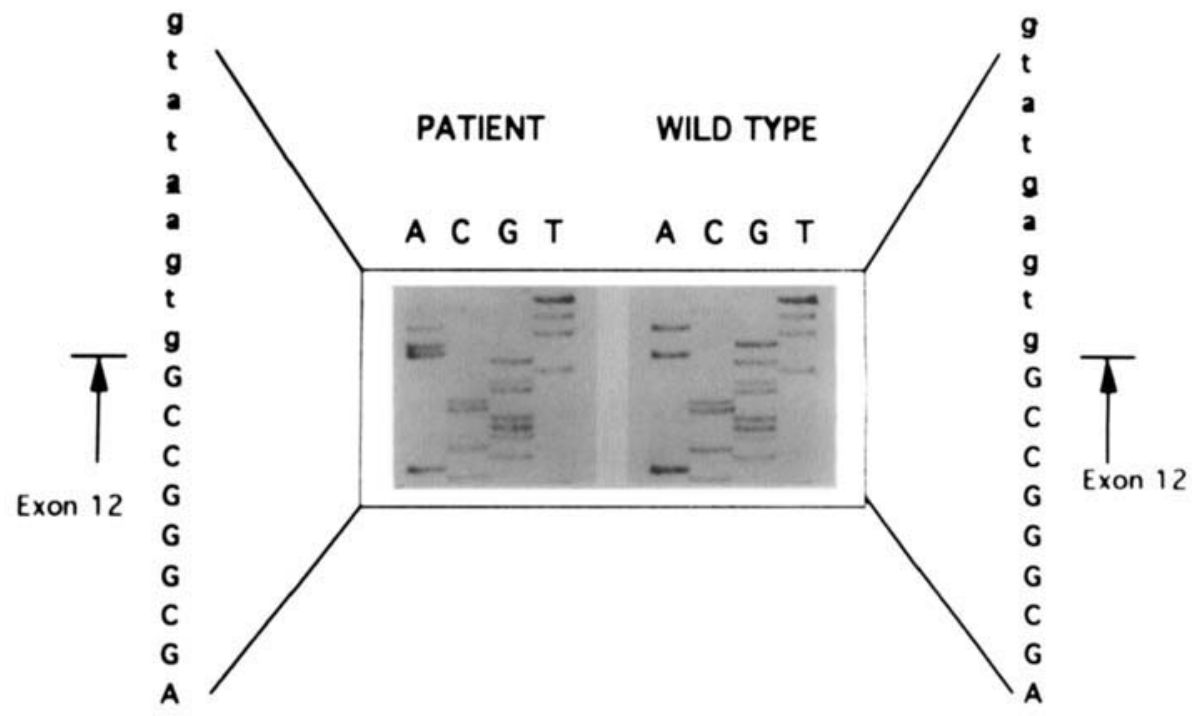

B.

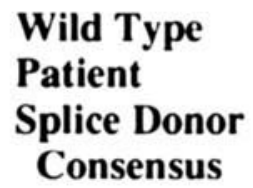

\section{AGCGGGCCGgtgagtatg AGCGGGCCGgtgaantatg CAGgtgagt \\ A a}

FIGURE 2. A. Missense mutation in nucleotide 700. T has been changed to $G$, substituting glycine for tryptophan in exon 8 , codon 234. B. Splicing donor mutation. The fifth intronic base within the splice donor consensus sequence of intron 12 shows a " $\mathrm{g}$ " to " $\mathrm{a}$ " change. Bottom shows the normal splice donor sequence compared to mutant.

For acute tyrosinemia type 1 , only a few mutations in the FAH gene have been described (Table 2). The first reported mutation was from a FrenchCanadian patient in which an asparagine to isoleucine change in codon 16 was identified in the FAH cDNA (Phaneuf et al., 1992). This patient suffered a neurological crisis in infancy. We can conclude that the N16I allele does not contribute substantial FAH activity since the patient, heterozygous for this mutation, expressed the acute form of the disorder. Similarly, an intron 12 splice donor mutation, expressed in the homozygous state in a French-Canadian patient (Grompe and $\mathrm{Al}$ Dhalimy, 1993), resulted in severe disease, so that 


\section{3}

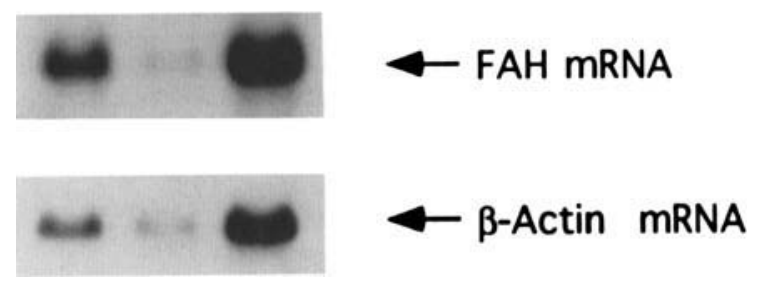

FIGURE 3. Expression of FAH mRNA in fibroblasts. Lane 1, normal control; lane 2, patient; lane 3 , patient's mother. The filter was probed with ${ }^{32} \mathrm{P}$-labeled FAH $\mathrm{CDNA}$. The same filter was stripped and reprobed with ${ }^{32} \mathrm{P}$-labeled $\beta$-actin cDNA as an internal standard.

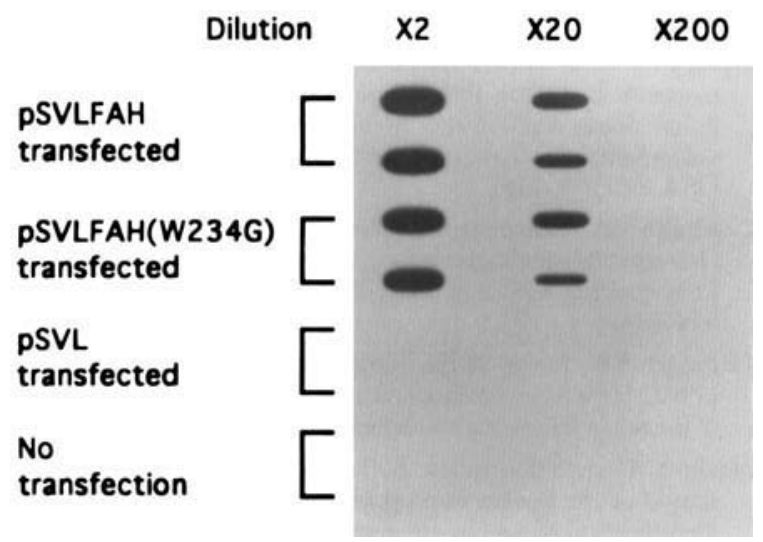

FIGURE 4. Slot blots of FAH mRNA in COS cells transfected with pSVL vector containing no DNA, normal FAH DNA, or mutant FAH DNA. Equal amounts of total RNA extracted from duplicate transfected or untransfected cell lines were blotted to nitrocellulose paper and probed with ${ }^{32} \mathrm{P}$-labeled FAH cDNA. RNA samples were diluted 2-, 20-, and 200-fold.

allele would not be expected to provide significant levels of FAH either.

The mild and chronic forms of tyrosinemia type 1 have been associated with a different set of mutant alleles (Table 2), but since only one of the two mutations has been identified in any given patient, the mutation responsible for the attenuated phenotype cannot be definitively determined.

In our patient, the W234G mutation probably did not provide the residual FAH activity necessary for expression of a chronic phenotype. First, on theoretical grounds, the W234G mutation replaces a nonpolar tryptophan residue with an uncharged but polar glycine residue. This would alter the region's hydrophobicity and may result in a tertiary structural change of the protein. Of interest, the region surrounding codon 234 of the $\mathrm{FAH}$ gene is conserved in rat and mouse, perhaps reflecting the critical nature of the amino acid sequence of this region.
Second, fibroblasts from the patient's mother exhibited $50 \%$ of the normal FAH activity. Since this was presumably derived from her normal allele, the W234G allele would contribute negligible FAH activity. Third, the W234G mutation provided virtually no FAH activity when expressed in COS cells transfected with pSVLFAH(W234G). Although the W234G allele may produce finite but undetectable quantities of $\mathrm{FAH}$, our limit of detection in the COS cell assay was 0.2 unit/g protein, or $\sim 3 \%$ of that for the normal FAH allele (Table 1).

The lack of FAH activity in the pSVLFAH(W234G)-transfected COS cells occurred despite the presence of abundant FAH RNA (Fig. 4), consistent with the normal size and $50 \%$ amount of mRNA in the patient's own fibroblasts (Fig. 3). The finding of significant FAH mRNA of normal size in a chronic tyrosinemia type 1 patient with virtually no residual $\mathrm{FAH}$ enzymatic activity has been previously reported in a Norwegian patient heterozygous for the A134D mutation (Labelle et al., 1993).

If residual FAH activity cannot be accounted for by the missense mutation, perhaps the splicing mutation is responsible. The French-Canadian splicing mutation, which in the homozygous state results in an acute phenotype, is associated with cryptic splicing within intron 12 and a 105 bp insertion (Grompe and Al-Dhalimy, 1993). When PCR primers between nucleotides 631 and 1,391 were employed, this insertion was also apparent in our patient (Fig. 1A). When PCR primers between nucleotides 631 and 1,280 were employed, however, deletion of exon 12 (with or without deletion of exon 13) was observed rather than the $105 \mathrm{bp}$ insertion. The different results depending upon the 3' primer employed suggest that in vitro PCR findings may not reflect the in vivo situation. Specifically, some correct splicing may well occur despite the splice site mutation (Fig. 1B, Fig. 3), effecting a mild phenotype. Indeed, correct splicing has been demonstrated for splicing mutations involving other diseases, such as adenosine deaminase deficiency, even when the invariant first nucleotide of the $5^{\prime}$ splice donor sequence has been mutated (Arredondo-Vega et al., 1994). In fact, this splicing mutation was associated with a mild phenotype in one sibling despite manifesting as a severe phenotype in his brother. Clearly, we have not yet identified all the determinants of the extent of correct splicing in splice site mutations.

An alternative explanation for our patient's mild phenotype lies in the possibility of mosaicism 
TABLE 2. FAH Mutations in Tyrosinemia Type 1 Patients

\begin{tabular}{|c|c|c|c|c|}
\hline Mutation & Status & $\begin{array}{l}\text { Clinical } \\
\text { course }\end{array}$ & Ethnicity & Reference \\
\hline Splice donor (intron 12) & Homozygote & Acute & Fr. Can. & Grompe and Al-Dhalimy, 1993 \\
\hline N16I & Heterozygote & Neurol. crisis & Fr. Can. & Phaneuf et al., 1992 \\
\hline V166G & Heterozygote? & Chronic? & Iranian & Grompe and Al-Dhalimy, 1993 \\
\hline Nonsense, codon $357 / 364$ & Heterozygote & Mild & Fr. Can./English & Grompe and Al-Dhalimy, 1993 \\
\hline A134D & Heterozygote & Chronic & Norwegian & Labelle et al., 1993 \\
\hline & & & Turkish/Norwegian & Rootwelt et al., 1994 \\
\hline P342L & Heterozygote & Chronic & Norwegian & Rootwelt et al., 1994 \\
\hline Splice donor (intron 12)/W234G & Heterozygote & Chronic & American & This study \\
\hline
\end{tabular}

resulting in different FAH expression in different tissues. Kwittingen (1993) recently reported two Norwegian patients with chronic tyrosinemia type 1 , in whom FAH immunoreactivity was present in certain areas of a tyrosinemia patient's liver, apparently representing clonal expansion of cells expressing significant FAH activity. This selective expression could account for enormous variability in the clinical manifestations of patients with the same splicing defect but variable amounts of residual, correct splicing.

Hence, it may be impossible to predict the severity of the tyrosinemia type 1 phenotype based upon the genotype or even based upon residual FAH activity measured in nonhepatic tissue. Ultimately, a liver biopsy for FAH activity may be required to determine a prognosis and the consequent suitability of the different therapeutic strategies available.

\section{ACKNOWLEDGMENTS}

The authors thank Dr. Markus Grompe for his helpful suggestions and discussions, and Theresa Gahl for assistance in sequencing.

\section{REFERENCES}

Agsteribbe E, van Faassen $H$, Hartog MV, Reversma T, Taanman JW, Pannekoek H, Evers RF, Welling GM, Berger R (1990) Nucleotide sequence of cDNA encoding human fumarylaceoacetase. Nucleic Acids Res 18:1887.

Arredondo-Vega FX, Santisteban I, Kelly S, Schlossman CM, Umetsu DT, Hershfield MS (1994) Correct splicing despite mutation of the invariant first nucleotide of a $5^{\prime}$ splice site: A possible basis for disparate clinical phenotypes in siblings with adenosine deaminase deficiency. Am J Hum Genet 54:820830.

Ausubel FM, Brent R, Kingston RE, Moore DD, Seidman JG, Smith JA, Struhl K (1987) Current Protocols in Molecular Biology. New York: John Wiley \& Sons.

De Braekeleer M Larochelle J (1990) Genetic epidemiology of hereditary tyrosinemia in Quebec and in Saguenay-Lac-StJean. Am J Hum Genet 47:302-307.

Goldsmith LA and Laberge C (1989) Tyrosinemia and related disorders. In Scriver CR, Beaudet AL, Sly W, Valle D (eds): The Metabolic Basis of Inherited Disease. New York: McGraw.Hill, pp. 547-562.
Grompe M, Al-Dhalimy M (1993) Mutations of the fumarylacetacetate hydrolase gene in four patients with tyrosinemia, type 1. Hum Mutat 2:85-93.

Grompe M, Al-Dhalimy M (1994) Creation of a murine model of hereditary tyrosinemia type 1. Pediatr Res 35:895 (Abstract).

Klebig ML, Russel LB, Rinchik EM (1992) Murine fumarylacetoacetate hydrolase (Fab) gene is disrupted by a neonatally lethal albino deletion that defines the hepatocyte-specific developmental regulation 1(hsdr-1) locus. Proc Natl Acad Sci USA 89:1363-1367.

Kvittingen EA, Halvorsen S, Jellum E (1983) Deficient fumarylacetoacetate hydrolase activity in lymphocytes and fibroblasts from patients with hereditary tyrosinemia. Pediatric Res 17 : 541-544.

Kvittingen EA, Rootwelt $\mathrm{H}$, Brandtzaeg P, Bergan A, Berger $\mathrm{R}$ (1993) Hereditary tyrosinemia type 1: Self induced correction of the fumarylacetoacetase defect. J Clin Invest 91:1816-1821.

Labelle Y, Phaneuf D, Leclerc B, Tanguay RM (1993) Characterization of the human fumarylacetoacetate hydrolase gene and identification of a messense mutation abolishing enzymatic activity. Hum Mol Genet 2:941-946.

Laberge C, Grenier A, Valet JP, Morissette J (1990) Fumarylacetoacetase measurement as a mass-screening procedure for hereditary tyrosinemia type 1 . Am J Hum Genet 47:325-328.

Lindstedt S, Holme E, Lock EA, Hjalmarson O, Strandvik B (1992) Treatment of hereditary tyrosinemia type- 1 by inhibition of 4-hydroxyphenylpyruvate dioxygenase. Lancet 340: 813-817.

Mitchell G, Larochelle J, Lambert M, Michaud J, Grenier A, Ogier H, Gauchier M, Lacroix J, Vanasse M, Larbrisseau A, Paradis $K$, Weber A, Lefervre $Y$, Melancon S, Dallaire I. (1990) Neurologic crises in hereditary tyrosinemia. N Engl J Med 322:432-437.

Mullis K, Faloona F, Scharf F, Saiki R, Horn G, Erlich H (1986) Specific enzymatic amplification of DNA in vitro: The polymerase chain reaction. Cold Spring Harbor Symp Quant Biol 51:263-271.

Paradis K, Weber A, Seidman EG, Larochelle J, Garel L, Lenaerrs C, Roy CC (1990) Liver transplantation for hereditary ty. rosinemia: The Quebec experience. Am J Hum Genet 47:338342.

Phaneuf D, Labelle $Y$, Berube D, Arden K, Cavenee W, Gagne R, Tanguay RM (1991) Cloning and expression of the cDNA encoding human fumarylacetoacetate hydrolase, the enzyme deficient in hereditary tyrosinemia: Assignment of the gene to chromosome 15. Am J Hum Genet 48:525-535.

Phaneuf D, Lambert M, Laframboise R, Mitchell G, Lettre F, Tanguay RM (1992) Type 1 hereditary tyrosinemia. Evidence for molecular heterogeneity and identification of a causal mutation in a French Canadian patient. J Clin Invest 90:11851192.

Rootwelt $\mathrm{H}$, Kvittingen EA, Hoie K, Agsteribbe E, Hartog M, van 
Faassen H, Berger R (1992) The human fumarylacetoacetase gene: Characterization of restriction fragment length polymorphisms and identification of haplotypes in tyrosinemia type 1 and pseudodeficiency. Hum Genet 89:229-233.

Rootwelt H, Chou J, Gahl WA, Berger R, Coskun T, Brodtkorb E, Kvittingen EA (1994) Two missense mutations causing tyrosinemia type 1 with presence and absence of immunoreactive fumarylacetoacetase. Human Genetics 93:615-619.

Ruppert S, Kelsey G, Schedl A, Schmid E, Thies E, Schutz G (1992) Deficiency of an enzyme of 1-tyrosine metabolism underlies altered gene expression in newborn liver of lethal albino mice. Genes \& Dev 6:1430-1443.

Sambrook J, Fritsch EF, Maniatis T (1989) Molecular Cloning: A Laboratory Manual. Cold Spring Harbor, NY: Cold Spring Harbor Laboratory Press.
Scott CR, Feldman K, Holme E, Lindstedt S (1994) Metabolic blockade: An effective therapy for tyrosinemia-1. Pediatr Res 35:207A (Abstract).

Smith PK, Krohn RI, Hermanson GT, Mallia AK, Gartner FH, Provenzano MD, Fujimoto EK, Goeke NM, Olson BJ, Klenk DC (1985) Measurement of protein using bicinchoninic acid. Anal Biochem 150:76-85.

Tanguay RM, St-Louis M, Demers SI, Leclerc B, Al-Dhalimy M, Grompe M (1993) Identification of predominant mutation in hereditary tyrosinemia type 1 patients from Quebec. Am J Hum Genet 954 (Abstract).

Weinberg AG, Mize CE, Worthen HG (1976) The occurrence of hepatoma in the chronic form of hereditary tyrosinemia. J Pediatr 88:434-438. 